\title{
ANALISIS VARIASI POSISI KLIP JARUM SKEP TERHADAP UNJUK KERJA MESIN MOTOR YAMAHA JUPITER Z 110 cc TAHUN 2008
}

\author{
Puji Supriyanto \\ Teknik Mesin, Fakultas Teknik \\ Universitas Maarif Hasyim Latif, Sidoarjo, Indonesia \\ e-mail : pujisupriyanto18@gmail.com
}

\begin{abstract}
ABSTRAK
Pada perkembangan teknologi sepeda motor di Indonesia khususnya di temukan bahwa perkembangannya motor standar keluaran pabrik mengarah pada tingkat efisiensi yang tinggi. Hal itu pulalah yang menyebabkan membuat pabrikan membuat setingan yang "paten" agar settingan pabrik sebisa mingkin tidak berubah terlau banyak setelah motor digunakan oleh para pemakainya. Contoh nyata salah satunya pada teknologi jarum skep pada karburator sepeda motor. Umumnya jarum skep sepeda motor tipe-tipe terdahulu dapat di setel dengan penambahan alur pada batang ulir jarum skep tersebut. Akan tetapi sangat berbeda pada sepeda motor keluaran terkini. Penelitian ini memiliki tujuan sebagai berkut Untuk mengetahui posisi ring jarum skep terhadap unjuk kerja mesin sepeda motor Yamaha Jupitez yang meliputi daya motor dan konsumsi bahan bakar. Untuk mengetahui dimana posisi ring jarum skep yang paling optimum dan konsumsi bahan bakar yang paling irit pada sepeda motor Yamaha Jupiter. Metode penelitian yang di laksanakan ini adalah metode experimental murni yang di gunakan untuk variasi ring skep terhadap unjuk kerja pada motor bensin 4 langkah. Caranya adalah dengan membandingkan unjuk kerjanya pada motor bensin 4 langkah yang sudah menggunakan sistem pengapian CDI. Adapun tempat/ bengkel untuk pelaksanaan DYNOTEST beralamat di jalan undaan no 115 Banyuwangi motor. Hasil dari pengujian dan perhitungan, didapatkan posisi klip jarum skep yang paling baik digunakan pada sepeda motor yamaha jupiter z $110 \mathrm{cc}$ yaitu posisi klip jarum skep alur 0 pada rpm 2000 mampu menghabiskan bahan bakar 357,16 gr/jam, rpm 3000 505,87 gr/jam, rpm 4000 597,95 gr/jam, rpm 5000 865,89gr/jam serta Daya sebesar 6.1 HP dan Torsi 6.72Nm.
\end{abstract}

Kata kunci : Daya, Dynotest , Klip jarum skep, Mesin motor, Torsi

\section{PENDAHULUAN}

Pada perkembangan teknologi sepeda motor di Indonesia khususnya di temukan bahwa perkembangannya motor standar keluaran pabrik mengarah pada tingkat efisiensi yang tinggi. Hal itu pulalah yang menyebabkan membuat pabrikan membuat setingan yang "paten" agar settingan pabrik sebisa mingkin tidak berubah terlau banyak setelah motor digunakan oleh para pemakainya.

Akan tetapi kenyataanya pemilik motor sendiri ada sebagian mereka yang merasa tidak puas dengan performa sepeda motor ala standar pabrik. Hal ini di dasari beberapa hal, salah satunya karena kebutuhan tiap manusia pada dasarnya sangat berbeda satu sama lain.

Contoh nyata salah satunya pada teknologi jarum skep pada karburator sepeda motor. Umumnya jarum skep sepeda motor tipetipe terdahulu dapat di setel dengan penambahan alur pada batang ulir jarum skep tersebut. Akan tetapi sangan berbeda pada sepeda motor keluaran terkini. Produsen malah memuatnya tak bisa di setel.

Mungkin bagi sebagian orang tak terlalu mempedulikan hal ini. Tapi di lain pihak, ada juga yang kurang puas dengan hal ini. Bagi yang mereka penyuka speed or performance dan punya uang lebih, akan mudah bagi mereka untuk mengganti komponen karburator yang mempunyai spek kompetiosi yang tentunya harganya tak bisa dibilang murah, dan biasanya juga tak bisa instant dan tidak langsung dengan settingan standarnya. Padahal apabila kita kreatif sedikit dan mau repot tak susah kok untuk mengakali hal ini. Khusus para pengguna generasi honda $125 \mathrm{cc}$ mulai kirana, karisma sampai supra $\mathrm{x} 125$. bisa mengaplikasi tips ini.

\section{METODE PENELITIAN}

Metode penelitian yang di laksanakan ini adalah metode experimental murni yang di gunakan untuk variasi posisi klip jarum skep terhadap unjuk kerja pada motor bensin 4 langkah. Caranya adalah dengan membanding- 
kan unjuk kerjanya pada motor bensin 4 langkah yang sudah menggunakan sistem pengapian CDI. Adapun tempat/ bengkel untuk pelaksanaan DYNOTEST beralamat di jalan undaan no 115 Banyuwangi motor.

\section{Pelaksaan Penelitian}

Mempersiapkan instalasi utama yang dirangkai menjadi satu kesatuan pada rangka. kemudian dilakukan pengujuian pada alat untuk mengetahui apakah alat itu berfungsi seperti yang diharapkan.

\section{Pengujian posisi klip jarum skep terhadap konsumsi bahan bakar}

Untuk mengetahui konsumsi bahan bakar yang digunakan, yaitu dengan cara menempatkan bahan bakar pada tabung ukur yang telah disediakan, kemudian menggunakan selang bahan bakar disalurkan ke karburator. Sehingga bahan bakar yang akan habis akan bisa diliahat langsung di lihat. Dengan posisi klip jarum skep alur 0 sampai dengan 4 pada rpm 2000 selanjutnya baru dilakukan pencatatan waktu yang telah terpakai untuk menghabiskan bahan bakar sebanyak volume tertentu.

Untuk pengambilan data selanjutnya sama seperti pengambilan data pada rpm 2000, dengan posisi klip jarum skep yang sama pula tetapi dengan rpm yang berbeda yaitu rpm 3000, 4000 dan 5000.

Pengujian dilakukan dengan kondisi sepeda motor berhenti dan pengujian dilakukan lebih dari 1 kali agar mendapatkan hasil yang maksimal.

\section{Pengujian posisi klip jarum skep terhadap daya motor}

Untuk pengujian daya menggunakan alat yaitu dynotest. Untuk pengujian pertama menggunakan posisi klip jarum skep alur 0, sebelum pengujian dilakukan, cek alat agar berfungsi dengan baik. Setelah itu baru pengujian dilakukan. Naikkan sepeda motor pada alat dynotest lalu garpu depan di ikatkan pada pengunci yang tersedia dan roda belakang di naikkan di atas roller dynotest, kemudian salah satu kabel dynotest dihubungkan dengan kabel tegangan tinggi dari koil ke busi sepeda motor.

Selanjutnya nyalakan sepeda motor dan masukkan pada gigi 3, sambil melihat monitor dynotest naikkan gas sampai 4000 rpm seketika itu juga tekan tombol penghubung dari dynotest 1 kali dan pada saat itu juga di naikkan gas sampai maksimal, pada saat rpm paling tinggi tekan tombol penghubung dari dynotestsekali lagi untuk memperoleh hasilnya, kemudian gas langsung diturunkan dan hasilnya bisa langsung dilihat pada monitor yang ada pada dynotest.

Untuk mendapatkan hasil yang maksimal pengujian dilakukan lebih dari 1 kali, dan hasil paling tinggilah yang diambil. Untuk pengujian posisi ring jarum skep selanjutnya sama seperti pengujian pada alur 0 di atas, tetapi dengan posisi ring jarum skep yang berbeda yaitu alur 0 sampai alur 4

\section{HASIL DAN PEMBAHASAN}

Setelah dilaksanakan pengujian, maka data yang diambil dimasukan dalam tabel 1 dan 2 berikut ini adalah tabel-tabel tersebut

Tabel 1, Hasil pengujian daya motor

\begin{tabular}{|c|c|c|}
\hline Posisi klip jarum skep & Max power & Max torque \\
\hline Alur 0 & $6.1(6.2) \mathrm{HP} / 7243 \mathrm{rpm}$ & $6.72 \mathrm{Nm}(6.83) / 5253$ \\
\hline Alur 2 & $7.9(8.3) \mathrm{HP} / 6929 \mathrm{rpm}$ & $8.69 \mathrm{Nm}(9.28) / 5823$ \\
\hline Alur 4 & $8.0(8.4) \mathrm{HP} / 7211 \mathrm{rpm}$ & $8.69 \mathrm{Nm}(9.30) / 5925$ \\
\hline
\end{tabular}

Tabel 2. Hasil pengujian kosumsi bahan bakar kondisi berhenti

\begin{tabular}{|c|c|c|c|}
\hline $\begin{array}{c}\text { Posisi Klip Jarum } \\
\text { Skep }\end{array}$ & n (rpm) & $\begin{array}{c}\text { Volume bahan } \\
\text { bakar (ml) }\end{array}$ & $\begin{array}{c}\text { Waktu } \\
\text { (det) }\end{array}$ \\
\hline \multirow{3}{*}{ Alur 0 } & 2000 & 2 & 12,36 \\
\cline { 2 - 4 } & 3000 & 2 & 08,85 \\
\cline { 2 - 4 } & 4000 & 2 & 06,01 \\
\hline Alur 2 & 5000 & 2 & 04,80 \\
\hline
\end{tabular}




\begin{tabular}{|c|c|c|c|}
\hline \multirow{4}{*}{ Alur 4 } & 3000 & 2 & 10,00 \\
\cline { 2 - 4 } & 4000 & 2 & 08,35 \\
\cline { 2 - 4 } & 5000 & 2 & 05,11 \\
\hline \multirow{4}{*}{} & 2000 & 2 & 14,36 \\
\cline { 2 - 4 } & 3000 & 2 & 10,39 \\
\cline { 2 - 4 } & 4000 & 2 & 08,79 \\
\cline { 2 - 4 } & 5000 & 2 & 06,07 \\
\hline
\end{tabular}

Setelah melalui perhitungan di atas, maka hasil perhitungan konsumsi bahan bakar dengan kondisi sepeda motor berhenti pada putaran 2000 rpm, 3000 rpm, 4000 rpm dan 5000 rpm dapat dilihat pada tabel berikut

Tabel 3. Posisi klip jarum skep

\begin{tabular}{|c|l|l|l|l|}
\hline Posisi klip jarum skep & Rpm 2000 & Rpm 3000 & Rpm 4000 & Rpm 5000 \\
\hline Alur 0 & $357,16 \mathrm{gr} / \mathrm{jam}$ & $505,87 \mathrm{gr} / \mathrm{jam}$ & $597,95 \mathrm{gr} / \mathrm{jam}$ & $867,89 \mathrm{gr} / \mathrm{jam}$ \\
\hline Alur 2 & $359,26 \mathrm{gr} / \mathrm{jam}$ & $525,6 \mathrm{gr} / \mathrm{jam}$ & $629,46 \mathrm{gr} / \mathrm{jam}$ & $1028,57 \mathrm{gr} / \mathrm{jam}$ \\
\hline Alur 4 & $425,24 \mathrm{gr} / \mathrm{jam}$ & $593,89 \mathrm{gr} / \mathrm{jam}$ & $874,54 \mathrm{gr} / \mathrm{jam}$ & $1095 \mathrm{gr} / \mathrm{jam}$ \\
\hline
\end{tabular}



Gambar 2. Grafik konsumsi bahan bakar

Tabel 3. Hasil pengujian unjuk kerja

\begin{tabular}{|c|c|c|c|c|c|c|}
\hline \multirow{2}{*}{$\begin{array}{c}\text { Posisi klip } \\
\text { jarum skep }\end{array}$} & $\begin{array}{c}\mathbf{2 0 0 0} \\
\text { rpm }\end{array}$ & $\begin{array}{c}\mathbf{3 0 0 0} \\
\text { rpm }\end{array}$ & $\mathbf{4 0 0 0} \mathbf{~ r p m}$ & $\begin{array}{c}\mathbf{5 0 0 0} \\
\text { rpm }\end{array}$ & $\begin{array}{c}\text { Daya } \\
\text { (HP) }\end{array}$ & $\begin{array}{c}\text { Torsi } \\
\text { (Nm) }\end{array}$ \\
\hline Alur 0 & 402,75 & 559,74 & 774,07 & 856,89 & 7.9 & 8.69 \\
\hline Alur 2 & 450,77 & 491,21 & 586,60 & 727,29 & 8.3 & 8.85 \\
\hline Alur 4 & 474,79 & 517,83 & 713,16 & 790,37 & 8.1 & 8.85 \\
\hline
\end{tabular}

Tabel 4. Hasil pengujian rangking unjuk kerja

\begin{tabular}{|c|c|c|c|c|c|c|c|}
\hline \multirow[b]{2}{*}{$\begin{array}{c}\text { Posisi klip } \\
\text { jarum skep }\end{array}$} & \multicolumn{4}{|c|}{ Konsumsi bahan bakar } & \multirow[b]{2}{*}{ Daya } & \multirow[b]{2}{*}{ Torsi } & \multirow[b]{2}{*}{ Jumlah } \\
\hline & $\begin{array}{c}2000 \\
\text { rpm }\end{array}$ & $\begin{array}{c}3000 \\
\text { rpm }\end{array}$ & $\begin{array}{c}4000 \\
\text { rpm }\end{array}$ & $\begin{array}{c}5000 \\
\text { rpm }\end{array}$ & & & \\
\hline Alur 0 & 1 & 1 & 1 & 1 & 1 & 1 & 6 \\
\hline Alur 2 & 2 & 2 & 2 & 2 & 2 & 2 & 12 \\
\hline Alur 4 & 3 & 3 & 3 & 3 & 3 & 3 & 18 \\
\hline
\end{tabular}


.Tabel 5. Hasil pengujian posisi klip jarum skep terhadap daya dan torsi

\begin{tabular}{|c|c|c|}
\hline $\begin{array}{c}\text { Posisi Klip } \\
\text { Jarum Skep }\end{array}$ & Max power & Max torque \\
\hline Alur 0 & $6.1(6.2) \mathrm{HP} / 7243 \mathrm{rpm}$ & $6.72 \mathrm{Nm}(6.83) / 5253$ \\
\hline Alur 2 & $7.9(8.3) \mathrm{HP} / 6929 \mathrm{rpm}$ & $8.69 \mathrm{Nm}(9.28) / 5823$ \\
\hline Alur 4 & $8.0(8.4) \mathrm{HP} / 7211 \mathrm{rpm}$ & $8.69 \mathrm{Nm}(9.30) / 5925$ \\
\hline
\end{tabular}

Pada rpm 2000 dengan posisi klip jarum skep alur 0 mampu menghabiskan bahan bakar paling sedikit yaitu $357,16 \mathrm{gr} / \mathrm{jam}$ dan yang paling banyak menghabiskan bahan bakar adalah posisi klip jarum skep alur 4 yaitu 425,24 gr/jam.

Pada rpm 3000 dengan posisi klip jarum skep alur 0 mampu menghabiskan bahan bakar paling sedikit yaitu 505,87 gr/jam dan yang paling banyak menghabiskan bahan bakar adalah posisi klip jarum skep alur 4 yaitu 525,6 gr/jam.

Pada rpm 4000 dengan posisi klip jarum skep alur 0 mampu menghabiskan bahan bakar paling sedikit yaitu 597,95 $\mathrm{gr} / \mathrm{jam}$ dan yang paling banyak menghabiskan bahan bakar adalah posisi klip jarum skep alur 4 yaitu 874,54 gr/jam.

Pada rpm 4000 dengan posisi klip jarum skep alur 0 mampu menghabiskan bahan bakar paling sedikit yaitu 867,89 $\mathrm{gr} / \mathrm{jam}$ dan yang paling banyak menghabiskan bahan bakar adalah posisi klip jarum skep alur 4 yaitu 1095 gr/jam.

\section{Hasil Pengujian Unjuk Kerja}

Dari Tabel 3. dan Tabel 4. ditunjukkan sebuah hasil pengujian unjuk kerja yaitu daya dan torsi. Untuk Tabel 3. di atas adalah untuk hasil yang paling baik. Pada Tabel 4. ditandai dengan angka 1 hasil yang lebih tinggi dan yang terendah berikutnya ditandai dengan angka 2 dan 3.

\section{Hasil Pengujian Daya dan Torsi}

Pada Tabel 5. dapat diketahui bahwa pada posisi klip jarum skep 0 mampu menghasilkan daya 6,1 HP pada $7243 \mathrm{rpm}$, sedangkan posisi klip jarum skep alur 2 menghasilkan daya 7,9 HP pada $6929 \mathrm{rpm}$ dan posisi klip jarum skep alur 4 menghasilkan daya 8,0 HP pada $7211 \mathrm{rpm}$.

Sedangkan untuk torsi pada posisi klip jarum skep alur 0 mampu menghasilkan torsi 6,72 $\mathrm{Nm}$ pada $5253 \mathrm{rpm}$, sedangkan posisi klip jarum skep alur 2 mampu menghasilkan torsi 8,69 $\mathrm{Nm}$ pada $5823 \mathrm{rpm}$, dan posisi klip jarum skep alur 4 mampu menghasilkan torsi 8,69 Nm pada $5925 \mathrm{rpm}$.

Sedangkan untuk torsi pada posisi klip jarum skep alur 0 mampu menghasilkan torsi 6,72 Nm pada $5253 \mathrm{rpm}$, sedangkan posisi klip jarum skep alur 2 mampu menghasilkan torsi 8,69 Nm pada $5823 \mathrm{rpm}$, dan posisi klip jarum skep alur 4 mampu menghasilkan torsi 8,69 Nm pada 5925 Dibawah ini menunjukkan grafik pengujian daya dan torsi sesuai pada Table 5 .

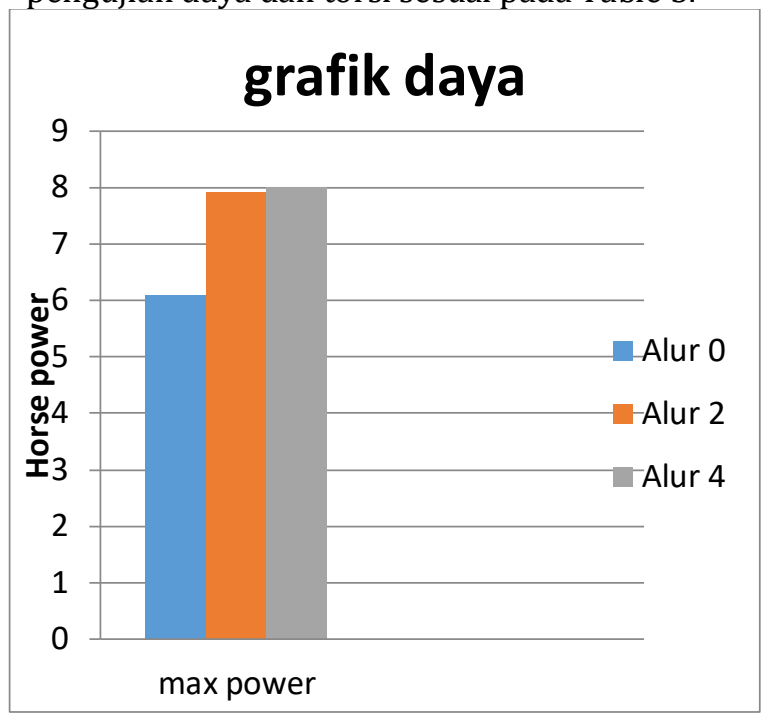

Gambar 3. Grafik pengujian daya

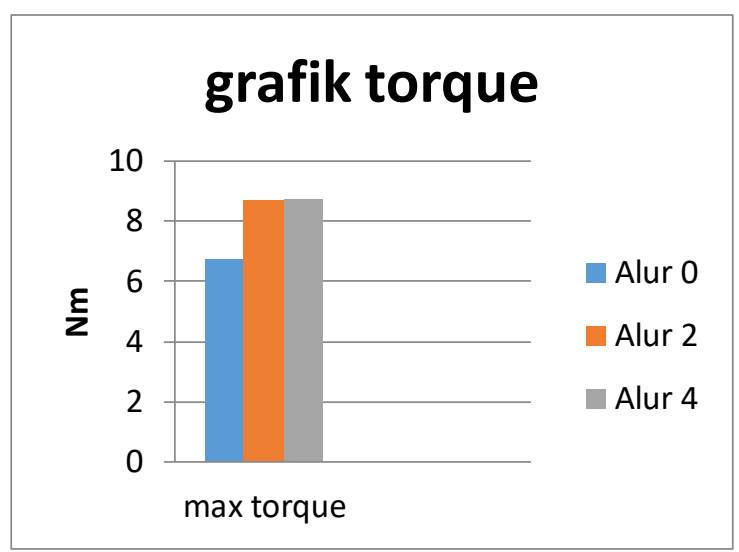

Gambar 4.3. Grafik torsi

\section{KESIMPULAN}

Dari metode penelitian yang saya lakukan didapatkan bebrapa kesimpulan, bahwa naik turun nya klip jarum skep akan berdampak pula pada konsumsi bahan bakar dan unjuk kerja mesin. Berikut penjabarannya :

1. Pada saat posisi klip jarum skep berada pada alur 0 maka konsumsi bahan bakar menjadi irit, kemudian jika posisi klip jarum skep diturunkan pada alur 2 maka 
konsumsi bahan bakar menjadi boros. Jika posisi klip jarum skep diturunkan kembali pada alur 4 maka konsumsi bahan bakar akan semakin boros.

2. Posisi klip jarum skep pada alur 0 mengkonsumsi bahan bakar paling irit yang biasa disebut dengan SETELAN KERING. Posisi klip jarum skep pada alur 4 mengkonsumsi bahan bakar paling banyak atau boros yang biasa disebut dengan SETELAN BASAH. Nah untuk posisi klip jarum skep pada alur 2 mengkonsumsi bahan bakar yang cukup (tidak irit juga tidak boros) setelan ini merupakan setelan yang ideal yang dibutuhkan oleh mesin.

3. Pengaruh posisi klip terhadap unjuk kerja mesin yaitu jika posisi klip jarum skep berda pada alur 4 maka konsumsi bahan bakar semakin boros dan daya kerja mesin semakin panas dan jika posisi klip jarum skep pada alur 0 maka konsumsi bahan bakar semakin irit dan daya kerja mesin semakin lamban

4. Pengaruh posisi klip jarum skep terhadap daya dan torsi dapat dilihat pada table 4.6 yang menyatakan bahwa alur 0 merupakan posisi yang baik yang mampu menghasilkan daya $6.1 \mathrm{HP}$ pada $7243 \mathrm{rpm}$, sedangkan untuk torsi posisi baik berada pada posisi jarum skep alur 0 yang mampu menghasilkan torsi $6.72 \mathrm{Nm}$ pada 5253 rpm.

\section{DAFTAR PUSTAKA}

Arikunto Suharsimi. 1992. Prosedur Penelitian Suatu Pendekatan Praktik. Jakarta : PT Rieneka Cipta.

Boentarto, Drs. 2005. Menghemat Bensin Sepeda Motor. Semarang : Effhar \& Dahara Prize.

Eko Putra Agfianto. 2002. Belajar Mikrokontroler AT89C51/52/55. Yogyakarta

Pakpahan Abigain. 1998. Motor Otomotif I. Bandung : Angksa.

Sudjana. 1991. Desain Dan Analisis Eksperimen. Bandung : Tarsito 1992. Service Auto Mobil. Bandung : Pustaka Setia.

Setiawan Sulhan. 2006. Mudah dan Menyenangkan Belajar Mikrokontroler.
Suganda Hadi \& Kageyama Katsumi. 1993. Pedoman Perawatan Sepeda Motor. Jakarta : Pradnya Paramita.

Wiranto Aris Munandar. 1988. Penggerak Mula Motor Bakar. Bandung : ITB Pers. 
MK Huda, dkk / Mechonversio, Vol. 1, No.1, Desember 2018, 12-17

Halaman ini sengaja dikosongkan 